\title{
Una vez más sobre la noción de responsabilidad histórica en Humanismo y terror
}

\author{
Claudio Cormick \\ CONICET/UBA-París VIII
}

\begin{abstract}
Resumen: En el presente trabajo, intentaremos volver sobre el problema de la evaluación histórico-politica de la acción según Merleau-Ponty, a la luz de sus formulaciones en Humanismo y terrory de su reactualización, en los últimos años, por comentaristas como Alexandre Hubeny, Leonardo Eiff y Jérôme Melançon. Procuraremos aquí presentar algunos argumentos contra dos tesis merleaupontianas intimamente relacionadas: la tesis de la evaluabilidad "objetiva" de las acciones, según la cual podría describirse el comportamiento de sujetos como constituyendo una "traición" o un "crimen" independientemente de cualquier atribución de intenciones a los agentes en cuestión y, más adelante, la tesis de la responsabilidad "objetiva" del propio agente, esto es, la afirmación según la cual los sujetos histórico-políticos pueden ser "responsables" o "culpables" por resultados de sus acciones que no hayan podido prever, o incluso sean exactamente opuestos a los que se proponian.
\end{abstract}

Palabras clave: Merleau-Ponty; historia; responsabilidad; acción; marxismo

Abstract: "Once again about the Notion of Political Responsibility in Humanism and Terror". In the present work we try to return to the problem of Merleau-Ponty's historic and political evaluation of action in the light of his accounts in Humanism and Terror and their updating in the last years by commentators such as Alexandre Hubeny, Leonardo Eiff and Jérôme Melançon. We will present some arguments against two very close related theses by Merleau-Ponty: that of the "objective" evaluation of action, which holds that the subjects behavior can be described as constituing a "betrayal" or a "crime" independently of any attribution of intentions to the agents and the thesis of the "objective" responsibility of the agent, that is, the tenet that affirms that the historic and political subjects can be "responsible" or "guilty" for an outcome of their actions, that they cannot have foreseen or can be the exac opposite for what they intended.

Key Words: Merleau-Ponty; history; responsability; action; Marxism 
1. La evaluación según las intenciones y según los resultados: sobre las nociones de "crimen objetivo" y "traición objetiva"

Como es sabido, Merleau-Ponty toma como punto de partida la novela de Arthur Koestler, El cero y el infinito, para acercarse a los problemas de la responsabilidad histórica. El libro presenta una versión ficcionalizada del caso de Nicolai Bujarin, cuya trayectoria desde una política activa de oposición a Stalin hasta la declaración de su propia culpabilidad en uno de los "Juicios de Moscú" es analizada por el novelista como el itinerario -inevitable, según Koestler, para un marxista políticamente caído en desgracia- de una forzosa aceptación del veredicto de la Historia sobre el auténtico sentido de las acciones emprendidas, sentido que no emerge de las intenciones subjetivas sino de las consecuencias de tales actos. Merleau-Ponty no considera sobre Bujarin, como tampoco Koestler sobre su doble ficcional Rubashov, que pueda declarárselo culpable en el sentido en que los Juicios pretendian mostrar la culpabilidad de los condenados: Bujarin no cometió actos de espionaje a favor de potencias extranjeras ni buscó sabotear la economía soviética. Con todo, bajo la premisa de que la politica bujarinista de oposición a Stalin habría debilitado las posiciones de la URSS frente a la agresión nazi en la Segunda Guerra Mundial -premisa que el fenomenólogo cree estar en condiciones de constatar retrospectivamente, evaluando los actos de la oposición antiestalinista a partir de la perspectiva abierta por la invasión de 1941-, Merleau-Ponty concluye que Bujarin sí es, sin embargo, culpable; aunque desde el punto de vista de una presunta evaluación "objetiva”, no vinculada a una atribución de intenciones, sino que analiza los resultados de sus acciones ${ }^{1}$. De acuerdo al fenomenólogo, si un actor histórico ha emprendido una acción que

\footnotetext{
1 Kolakowski remarca correctamente -como lo vemos a la luz de la falta de argumentos específicos del fenomenólogo para sostener esta premisa- que "Merleau-Ponty parece dar por sentado o considerar altamente probable" que si la oposición antiestalinista "hubiera tenido libertad de acción, habría debilitado considerablemente, y quizás paralizado, a la Unión Soviética frente a la inminente guerra con Alemania". Sin embargo, señala el filósofo polaco, este supuesto "no es meramente controvertido, sino extremadamente dudoso... Hoy, la sugerencia de MerleauPonty de que el terror de los 30's fue una condición necesaria para la victoria contra Alemania se ve, simplemente, fantasiosa. Ni tampoco faltaba evidencia en su momento" (Kolakowski, L., "Obsolete Therefore Instructive", en: The New York Review of Books, 3 de setiembre (1970), pp. 23-24), cursivas del autor. A los efectos de poder analizar el argumento merleaupontiano según las propias premisas del fenomenólogo, haremos abstracción de la débil base historiográfica del argumento de Merleau-Ponty y nos preguntaremos, en consecuencia, si, bajo el supuesto de que la oposición a Stalin hubiera debilitado la defensa de la URSS contra las propias intenciones de los
} 
se convierte en contrarrevolucionaria a causa de sus efectos indeseados, no es posible exculparlo subrayando que su intención no fue generar tales resultados; no es relevante, según Merleau-Ponty, efectuar este corte.

Siempre en torno a la figura ficcional de Rubashov, Merleau-Ponty explica la forma en que, para este, las acciones requeririan ser evaluadas desde el punto de vista de sus resultados y no de sus intenciones: "Honor, deshonor, sinceridad, mentira, estas palabras no tienen sentido para el hombre de la historia. No hay sino traiciones objetivas y méritos objetivos"2. En esta línea de análisis, Merleau-Ponty comenta que Rubashov se vería obligado a juzgarse según "la dura regla marxista que obliga a definir a un hombre no por sus intenciones sino por lo que hace, y una conducta no por su sentido subjetivo sino por su sentido objetivo"3. Su discrepancia con este tipo de análisis se restringe al hecho de que Koestler -y no el propio fenomenólogo- le atribuye al marxismo una visión sobre la historia de acuerdo con la cual este "sentido objetivo" de las acciones podria, al menos en principio, ser objeto de una prognosis, en virtud de lo cual nuestra acción quedaría liberada de los problemas asociados a la contingencia de la historia. No obstante, el desacuerdo sobre el carácter de este sentido objetivo y de las condiciones de su cognoscibilidad no hace mella en la circunstancia de que, para Merleau-Ponty igual que para el marxismo según Koestler, es sobre este sentido -previsible o no-, y no sobre las intenciones subjetivas que debe volcarse la evaluación de una acción ${ }^{4}$. Coincidiendo en este punto con el análisis de Koestler, Merleau-Ponty señala que es necesario "reconocer como

oposicionistas, podría inferirse, como lo hace el fenomenólogo, que aquellos serían responsables de una "traición". Esto no quiere decir, reiteremos, que suscribamos a la premisa en cuestión.

2 Merleau-Ponty, M., Humanisme et terreur, 8va. edición, París: Gallimard, 1947, p. 6; en adelante, Humanisme. Consúltese la traducción al español: Humanismo y terror, Eozitchner, L. (trad.), Buenos Aires: La Pléyade, 1965, p. 48, en adelante, se hará referencia a esta traducción colocándola entre paréntesis luego de la referencia a la edición original en francés anteriormente citada.

3 Humanisme, p. 9 (trad., p. 50).

4 En efecto, para Merleau-Ponty, "Rubashov bien sabe que, de esta historia totalmente determinada, nadie conoce nunca nada más que fragmentos: ...cada uno de nosotros no posee nada más que una 'imagen subjetiva' que no está en condiciones de confrontar con la historia en sí, siempre supuesta más allá de la humanidad. Pero... Koestler no concluye que es preciso abandonar el mito realista. Se proyecta solamente hacia el porvenir y, en la espera del dia feliz en que conoceremos con certeza cientifica la totalidad de la historia, nos abandona a nuestras divergencias y a nuestros conflictos" (Humanisme, p. 19 (trad., p. 61)). Por el contrario, para MerleauPonty, el marxismo bien entendido acepta que el significado objetivo que adquirirán nuestras acciones no puede ser previamente controlado por vía de una prognosis: "Aun suponiendo que exista, en el verdadero sentido de la palabra, una ciencia del pasado, nadie sostuvo nunca que existiese una ciencia del futuro, y los marxistas son los últimos en hacerlo. Existen perspectivas, pero... no se trata sino de un horizonte de probabilidades... que puede, a medida que nos aproximamos y que se convierte en presente, revelarse bastante diferente del que esperábamos" (Humanisme, p. 59 (trad., p. 100)). Esta interpretación no determinista del marxismo no fue, 
moral la preocupación comunista por el papel objetivo, la voluntad de verse desde afuera y en la historia"5.

Más adelante en el libro, cuando Merleau-Ponty analiza directamente el caso de Bujarin, dejando de lado el rodeo a través de la novela de Koestler, pueden quedar al margen, con ello, las discrepancias respecto de la atribución o no al marxismo de una "ciencia del futuro". Permanece, sin embargo, el acuerdo respecto de los criterios para evaluar la acción. Siguiendo la interpretación hecha por el fenomenólogo, si bien es cierto que "no hubo entre Hitler y Bujarin ninguna entrevista de Montoire", no obstante, "en un país que no conoció, casi desde 1917, sino situaciones-límites... la oposición podía aparecer como traición"6. Se trata de una traición "objetiva" en el sentido de que es irrelevante, para esta calificación de sus acciones, atribuir intención alguna: "Cualquier cosa que haya querido, incluso si se tratara de un porvenir más seguro para la revolución, subsiste la situación de que de hecho debilitaba a la URSS"7. Así, concluye el fenomenólogo, "los procesos de Moscú serían el drama de la honestidad subjetiva y la traición objetiva"8.

Recapitulando en aras de la mayor claridad posible, y si bien las posiciones de Merleau-Ponty bosquejadas hasta aquí necesitarán ser formuladas con mayor precisión, podemos hasta el momento notar que estamos en presencia de una tesis como la siguiente:

Tesis de la evaluabilidad "objetiva" de las acciones: ciertas acciones pueden ser descritas con términos evaluativos como "crimen" o "traición" sin que esta descripción requiera estar atribuyendo al sujeto de la acción las correspondientes intenciones; podemos por lo tanto hablar, por ejemplo, de "traición objetiva". Intentaremos a continuación discutir la plausibilidad que quepa atribuir a esta tesis.

2. "Crimen" o "traición" en el plano histórico-politico: sobre su presunta especificidad respecto de los planos moral o jurídico

Para poder emprender esta discusión, conviene previamente explicitar lo obvio, aunque no sea más que para evidenciar una objeción que tengamos

\footnotetext{
previsiblemente, del agrado de la ortodoxia representada por Lukács. Cf. Lukács, G., Existentialisme ou marxisme?, París: Nagel, 1948, especialmente pp. 210 y 234).

5 Humanisme, p. 24 (trad., p. 65).

6 Humanisme, p. 47 (trad., p. 88), cursivas del autor.

7 Ibid., cursivas del autor.

8 Ibid., cursivas del autor.

ARETÉ Revista de Filosofía, vol. XXVIII, N², 2016 / ISSN 1016-913X
} 
inmediatamente que descartar como superficial: prima facie, nociones evaluativas como "crimen" de hecho requieren, para ser utilizadas, que atribuyamos intenciones al sujeto de la acción; es así como típicamente distinguimos, por ejemplo, entre el crimen y el mero accidente o el error. Desde cierto uso ordinario del lenguaje, hablar de una "evaluación objetiva" de una acción en tanto que crimen no puede acceder al rango de tesis interesante y digna de discusión porque simplemente queda bloqueada por la incongruencia: hablar de "crimen objetivo" sería desde este punto de vista algo así como un círculo cuadrado. No obstante, precisamente para no prejuzgar todo el punto que está en discusión, tenemos que estar abiertos a la posibilidad de que se redefinan los términos en cuestión. Antes de evaluar la tesis merleaupontiana y arriesgarnos a rechazarla desde consideraciones que podrian resultar superficiales, tenemos que estar seguros de comprender lo que se nos está proponiendo. Podría ser que, en el terreno histórico-político, la evaluación de ciertas acciones como "crimenes" y de su sujeto como "responsable" o "culpable" involucre otros significados que los que estas palabras habitualmente evocan.

$\mathrm{Y}$ en efecto, en la propia letra de Humanismo y terror encontramos un intento de diferenciar la calificación de las acciones desde el punto de vista que -para sintetizar- podemos llamar histórico político, por un lado, y el que entra en juego en la evaluación jurídica, por el otro. El fenomenólogo señala, en efecto, que en un proceso como los juicios de Moscú, "[1]a culpabilidad no es... la unión evidente de un gesto definido con móviles definidos y consecuencias

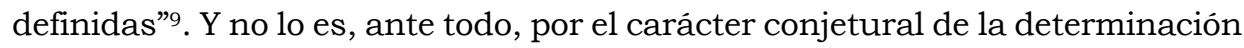
de tal culpabilidad, y por la escasez de información fáctica: "uno permanece en las cosas dichas, en ningún momento tiene la sensación de tocar, a través de ellas, el hecho mismo"; la culpabilidad "[n]o es la del criminal del cual se sabe por el testimonio de la portera que entró... en la casa del crimen... La trama de las causas, de las intenciones, de los medios y de los efectos de la actividad opositora no ha sido reconstruida. No hay más que algunos hechos en la bruma de significaciones movedizas"10. Con la referencia a estas "significaciones" ya tenemos un elemento adicional para el análisis: no se trata únicamente de las limitaciones del conocimiento que disponemos sobre los hechos del pasado, en los caracteres estrictos que podría haber descrito un testigo de tales hechos. El punto es que los Juicios de Moscú "se refieren a actos todavía abiertos hacia el

\footnotetext{
9 Humanisme, p. 28 (trad., p. 70).

${ }^{10}$ Humanisme, pp. 28-29 (trad., pp. 70-71). 
porvenir, que aún no son univocos y que no toman definitivamente un carácter criminal sino a condición de ser vistos desde la perspectiva del futuro que poseen los hombres situados en el poder"11; los actos de la oposición sometidos a proceso " no eran, en el verdadero sentido, actos de traición o de sabotaje, y no caían bajo el rigor de las leyes fundamentales del Estado sino mediante una interpretación"12. He aquí un punto importante: Merleau-Ponty insiste en que en el plano jurídico podemos caracterizar una acción como un crimen a partir de una perspectiva temporal recortada -paradigmáticamente, la perspectiva de lo que podría percibir un testigo- mientras que, cuando se trata de la responsabilidad histórico-política, una acción se tipifica como "crimen" en vistas de una perspectiva mucho más amplia, abierta a las nuevas determinaciones que aquella puede adoptar, a aquello en lo que ella se puede convertir a causa de ciertos posibles eventos posteriores que los acusadores no pueden haber constatado pero prevén. La condena a la oposición antistalinista en 1937 se basaria, por tanto, en una cierta perspectiva de futuro sobre los intereses de la URSS en un plazo no inmediato; en particular, sería en vistas de la agresión nazi de 1941 que, retrospectivamente, cualquier debilitamiento de la dirección política de la URSS se habría convertido en criminal ${ }^{13}$.

Sin embargo, insistamos: la tesis de que una acción A que realizamos en determinado momento puede tener una serie de efectos imprevistos e incluso indeseados, que ella puede iniciar una larga cadena causal de modo tal que sus consecuencias solo sean constatables mucho tiempo después y que, por lo tanto, cambien las propiedades relacionales de A (A se convierte en la causa de eventos muy posteriores a ella, precisamente a partir de que estos eventos hayan ocurrido) parece perfectamente descriptible sin un vocabulario tan cargado como el que nos habla de "crimen", y esto no requiere en absoluto negar la gravedad de las consecuencias en cuestión. Podemos hablar de errores o de accidentes que en un plazo no inmediato tuvieron consecuencias catastróficas y, por lo tanto, aquellos son acciones que, más allá de las intenciones de los agentes -pero también más allá de sus resultados inmediatos-, se convirtieron en

11 Humanisme, pp. 29-30 (trad., p. 71), cursivas del autor.

12 Humanisme, p. 29 (trad., p. 71), cursivas del autor.

${ }^{13}$ Es interesante notar que, al analizar el modo en que una acción pasada puede cambiar en virtud de sus relaciones con eventos futuros (la actividad de la oposición, según la interpretación estalinista, podria retrospectivamente convertirse en un factor debilitante de la URSS frente a la invasión nazi de 1941), las tesis de Merleau-Ponty confluyen con las del análisis de Danto sobre las "oraciones narrativas", centrales al relato histórico y que tienen la particularidad de describir un evento de un modo que sería imposible para un testigo del evento. $C f$. Danto, A., "Oraciones Narrativas", en: Narración y conocimiento, Buenos Aires: Prometeo Libros, 2014. 
acciones con tales consecuencias catastróficas. ¿Es esto suficiente para hablar de "crimen"? Si todo el punto de Merleau-Ponty se reduce a que, en virtud de posibles consecuencias cronológicamente distantes -no solo imprevistas por los sujetos, sino que quizá eran precisamente las consecuencias que ellos buscaron por todos los medios evitar-, llamemos "crimenes objetivos" lo que de otro modo habriamos podido llamar "errores" o "accidentes", entonces se trataría de una simple propuesta estipulativa de redefinición de nuestro vocabulario. Tenemos que determinar qué más está implicado en la tesis de la evaluación "objetiva” de las acciones.

Ahora bien, una hipótesis bastante razonable a la luz del texto merleaupontiano es asumir que para describir una acción como "traición" o "crimen" en sentido objetivo, en el terreno específicamente histórico-politico que estamos considerando, no solamente necesitamos atribuirle -como venimos considerando hasta aqui- ciertas consecuencias gravosas que -a diferencia del plano jurídico- no son inmediatas, sino también asociar la acción a un sujeto que sería "responsable" o "culpable" por ella. Hay motivos bastante razonables para incluir esta segunda determinación mínima en la reconstrucción de términos como "crimen": si todo el punto se redujera al plano de las consecuencias causales -porque, recordemos, hemos suprimido el plano de las intenciones-, no se vería siquiera por qué reducirse a acciones, contaría como "crimen" cualquier fenómeno con consecuencias causales lo suficientemente dañinas. Asimismo, no solamente los sujetos humanos que cometen errores o sufren accidentes pueden desencadenar cadenas causales; también puede hacerlo una plaga de langostas que ataque las cosechas y dé lugar a una hambruna. Merleau-Ponty necesita un concepto de "crimen" lo suficientemente amplio como para incluir lo que de otro modo describiriamos como errores o accidentes, pero evitar a la vez que quede rebajado a algo tan amplio que pueda aplicarse a las acciones humanas y al comportamiento de las langostas. Tendriamos entonces una tesis que vuelve más precisa, en los aspectos fundamentales, la formulación que introdujimos al final del apartado anterior:

Tesis de la evaluación "objetiva" de las acciones en el terreno históricopolitico: determinadas acciones pueden ser descritas con términos evaluativos como "crimen" o "traición", sin que esta descripción requiera estar atribuyendo al sujeto de la acción las correspondientes intenciones, en la medida en que (1) esta acción pueda tener, incluso en un plazo no inmediato, ciertas consecuencias sociales deletéreas (para la nación, para la revolución, etcétera), y (2) exista un sujeto agente que pueda ser "responsable" o "culpable" por ella. 
Esta nueva condición, naturalmente, hace que el título de "crimen objetivo" no sea un mero cambio nominal respecto de hablar de errores o accidentes: sitúa, como correlato de la declaración del crimen, la figura de un criminal "objetivo", de un responsable "objetivo", y esto tiene obvias consecuencias prácticas, como el castigo contra el criminal así decidido. Sin embargo, con ello no queda garantizado que hayamos tocado suelo firme: si antes la cuestión era qué podía realmente significar hablar de un crimen sin intenciones, ahora el peso del problema se desplaza a qué puede significar que estemos en presencia de un responsable del crimen que no haya tenido tales intenciones. Tenemos, entonces, que analizar una tesis como la siguiente:

Tesis de la "responsabilidad objetiva" del agente: la posibilidad de una evaluación de las acciones que no esté centrada en las intenciones del sujeto presupone, sin embargo, la determinación de la responsabilidad del propio sujeto; así, se puede ser responsable por una "traición objetiva", responsable por un "crimen involuntario".

\section{La redefinición de la responsabilidad en el plano histórico-politico}

Pasemos, entonces, a evaluar esta tesis. Merleau-Ponty introduce explícitamente, en efecto, la categoría de "responsabilidad histórica"14. Este tipo de responsabilidad, según el fenomenólogo, va más allá de categorías como "intención y acto, circunstancias y voluntad, objetivo y subjetivo", en tanto "[a]plasta al individuo en sus actos, mezcla lo objetivo y lo subjetivo, imputa las circunstancias a la voluntad; substituye así al individuo, tal como este se sentía ser, por un papel o un fantasma en el cual ya no se reconoce, pero en el cual debe reconocerse, porque es lo que ha sido para sus víctimas"15. De forma similar, el autor señala que "[1]a responsabilidad de un movimiento está determinada por el papel que desempeña en la coexistencia... Es posible tener que responder, pues, por actos de traición sin haber querido cometer ninguno"16. Por último, Merleau-Ponty se pronuncia en la misma línea cuando reclama contra la "regresión" de un pensamiento europeo empeñado en olvidar la condición trágica de la vida intersubjetiva que se conocía desde Grecia, e insiste contra aquel en la necesidad de reconocer "la pesadilla de una responsabilidad involuntaria y de una culpabilidad por posición que implicaba ya el mito de

14 Humanisme, p. 46 (trad., p. 87).

15 Humanisme, pp. 46-47 (trad., pp. 87-88).

${ }^{16}$ Humanisme, p. 63 (trad., p. 103).

ARETÉ Revista de Filosofía, vol. XXVIII, N² 2, 2016 / ISSN 1016-913X 
Edipo: Edipo no quiso desposar a su madre ni matar a su padre, pero lo hizo y el acto vale como un crimen"17.

Esta noción de una responsabilidad desligada de la atribución de intenciones ha sido tratada en un conjunto de intérpretes recientes, sorprendentemente, de un modo que sugiere que no habría en ella nada demasiado problemático. Sin embargo, necesitamos evaluar cuidadosamente su plausibilidad si, como hemos argumentado, de ella depende que, a su vez, la noción de "crimen objetivo" tenga algún significado aplicable. Veamos ante todo lo que nos señala Alexandre Hubeny: “[e]n el dominio político... la responsabilidad no tiene el mismo sentido que en el dominio moral o el jurídico, porque las acciones son otra cosa, y más, que intenciones seguidas de hechos"18. Ya nos detuvimos, a partir de la letra del propio Merleau-Ponty, en lo que concierne a las acciones mismas como puestas en relación con una proyección a futuro; tratemos ahora de entender qué estaría en juego en cuanto a la responsabilidad del sujeto de estas acciones. Lo importante es que para Hubeny, si bien -como ya consideramos- "todo lo que hacemos puede adquirir una significación inmensa y producir efectos incontrolables"19, especialmente en un contexto de inestabilidad como lo es el de una revolución. Sin embargo "al autonomizarse, al afectar el curso de las cosas y el destino de los hombres de otro modo que el que yo había querido, $m i$ acción no deja sin embargo de ser mia; yo sigo siendo su iniciador y sus consecuencias imprevistas deben poder ser vinculadas a un comienzo asignable" 20 .

Ahora bien, esto dista mucho de ser una solución aceptable, porque, así como el "crimen objetivo" necesita situarse en el lugar de un tertium entre la acción intencional, por un lado, y cualquier fenómeno no-intencional con consecuencias causales dañinas, por otro lado, así también la "responsabilidad objetiva" necesita ser un concepto lo suficientemente laxo como para no requerir la atribución de intenciones, pero no tan laxo como para quedar reducido a mera vinculación causal entre el agente y un conjunto de eventos. Si no queremos reducir la noción de "responsabilidad" a una enorme indeterminación -la cual dejaría en suspenso, por ejemplo, su conexión con ciertas prácticas tales como los premios y castigos-, no podemos decir solamente que un agente es responsable sobre la base de nociones causales como las que menciona

\footnotetext{
17 Humanisme, p. xxxv (trad., p. 33).

${ }^{18}$ Hubeny, A., “Jouer un rôle'. Action politique et responsabilité historique”, en: Bonan, R. (ed.), Merleau-Ponty: de la perception à l'action, Aix en Provenza: Universidad de Provenza, 2005, p. 78, cursivas del autor.

19 Ibid., p. 79, cursivas del autor.

20 Ibid., p. 80, cursivas del autor.
} 
Hubeny: "efectos", "iniciador" de la acción, "consecuencias imprevistas", "comienzo asignable" 21 . Esto no nos aclara cuál es la diferencia entre decir que un sujeto $\mathrm{S}$ es responsable de las consecuencias indeseadas de sus actos $\mathrm{y}$ decir que este sujeto $\mathrm{S}$ es, simplemente, el primer término de una cadena causal. Entre atribuir causación y atribuir responsabilidad debería haber alguna diferencia, que Merleau-Ponty (y Hubeny) se impiden poder describir en términos de intenciones. Sin embargo, nuevamente, los seres humanos tienen interacciones causales con su entorno tanto como también las tienen las plagas de langostas. Las "acciones" de las plagas de langostas han "engendrado" hambrunas, pero -pese a poder aplicar exactamente el mismo vocabulario causalista que encontramos en Hubeny- en principio no les atribuiriamos una "responsabilidad".

Nos cuesta también encontrar una respuesta precisa sobre el problema de la responsabilidad objetiva en la argumentación de Osborne Wiggins. Encontramos en él, como en Hubeny, una tesis empírica que no está en discusión: la de la existencia de consecuencias imprevistas de nuestros actos, y junto a ella, encontramos una conclusión extremadamente dudosa acerca de la noción de responsabilidad. Wiggins toma como punto de partida el escenario en que la atribución de responsabilidad sería indiscutible porque se daría una coincidencia entre intenciones y resultados ${ }^{22}$. No obstante, naturalmente, el punto consiste en lograr ampliar esta atribución de responsabilidad también hacia los resultados imprevistos. Ellos existen, desde ya; al igual que Hubeny, el comentarista norteamericano remarca que "[n]unca hay ninguna forma de asegurar una coincidencia entre la intención y las consecuencias de la acción. Al actuar incluso con el mejor de los motivos, puedo... lastimar o destruir a otras personas"; reciprocamente, incluso "las peores intenciones pueden generar el bien para la humanidad". No vemos ningún problema hasta aquí; pero este se asoma cuando Wiggins deduce de ello que "[e]sta falta de coincidencia entre la intención y el logro muestra la inevitabilidad de la culpa, la arbitrariedad de

${ }^{21} \mathrm{O}$ en otro pasaje cuyo vocabulario es igualmente causal: "la condena, en los procesos de Moscú, se refiere menos a hechos de traición verificados que... a los efectos, reales o supuestos, que una actitud de oposición puede engendrar en la conciencia revolucionaria de las masas" (ibid.), cursivas del autor.

22 "La responsabilidad política no plantearía ningún problema real si la acción... formara un todo unitario e indivisible. Si mi acción siguiera perfectamente la dirección esbozada en mi intención, entonces el futuro proyectado inevitablemente coincidiria con el futuro realizado. Esta identidad asegurada entre plan original y resultado final me haria responsable por ambos" (Wiggins, O.P., "Political Responsibility in Merleau-Ponty's Humanism and Terror", en: Man and World, v. XIX (1986), pp. 275-291, p. 276).

ARETÉ Revista de Filosofía, vol. XXVIII, N², 2016 / ISSN 1016-913X 
la inocencia, y el carácter elusivo de la pureza moral"23. Esta conclusión ya es algo mucho más problemático.

Wiggins cuestiona la posición según la cual "que las personas solo son responsables por las ‘buenas intenciones' de sus acciones” y "[1]as consecuencias de la obra... no son culpa del actor que no las buscó"24; ellas se tornan, bajo esta orientación, "separadas de la persona que actúa", "despersonalizadas y objetivadas", "eventos causales impersonales, que no pueden atribuírsele a ningún agente moral"25. Aunque Wiggins no reivindique la posición simétricamente opuesta a este "liberalismo" -que sería según él un "fenomenalismo moral" para el cual las acciones deben ser únicamente evaluadas desde el punto de vista de los resultados constatables ${ }^{26}$, el hecho es que, en cualquier caso, el recorte de la responsabilidad según el molde de las intenciones sería -señala el intérprete siguiendo a Merleau-Ponty-reduccionista: las consecuencias son atribuibles a los agentes morales; como agente moral ciertamente soy "lo que soy para mí mismo", pero también soy "lo que soy para los otros" 27 . Sea que la tesis se formule con el vocabulario de la "culpabilidad" o el de "atribución de los resultados a un agente moral", el problema es el mismo con el que venimos bregando: ¿qué quiere decir, cuando hemos dejado al margen las intenciones, ser "responsable"?

A efectos de aclarar el terreno de la discusión, podemos esquematizar la posición de Wiggins (y también la de Hubeny, aunque este no mencione explícitamente la primera de las tesis) en los siguientes términos:

1) Los sujetos son responsables por sus acciones deliberadas. [Tesis fuera de discusión, aceptada tanto por Merleau-Ponty como por sus adversarios y que por lo tanto sirve de punto de partida].

2) Estas acciones humanas deliberadas pueden tener consecuencias imprevistas (las "buenas" intenciones pueden tener resultados desastrosos y a la inversa). [Tesis empírica bastante mínima].

Por lo tanto, según esta argumentación,

3) Los sujetos son responsables también por las consecuencias imprevistas de sus acciones deliberadas.

\footnotetext{
${ }^{23}$ Ibid., p. 277, cursivas del autor.

${ }^{24}$ Ibid., pp. 277-278.

25 Ibid., p. 278.

${ }^{26}$ Según esta posición, "ser es ser percibido por otros. El significado de mi acción yace exclusivamente en el impacto que ella tiene en las vidas de los otros" (ibid., cursivas del autor).

27 Ibid., p. 277.
} 
Como se notará, la argumentación es muy simple y recurre a un tipo de transitividad, que lleva de (1) "soy responsable por A" y (2) "A causa C", a (3) "soy responsable por C". No obstante, si este tipo de transitividad pudiera deberse a que el término "responsable" tiene él mismo un sentido puramente causal (el sujeto es "el comienzo asignable de la acción", y así sucesivamente), entonces la conclusión quedaría probada, pero porque lo que enuncia es una trivialidad. Aquí, todo el punto se reduciria a "las consecuencias imprevistas de los actos de un agente se vinculan (causalmente) con el agente", lo cual francamente no nos lleva más allá de lo que está bastante claramente contenido en la noción misma de "consecuencias". En adición, dado que bajo esta interpretación de "responsable" la posición es una trivialidad, su negación sería literalmente un absurdo. Si el adversario de Merleau-Ponty negara el tipo de transitividad propuesto aquí -esto es, si afirmara (1) y (2) pero negara (3)-, tendría que ser concebido como un personaje que negara tener relación causal con las consecuencias imprevistas de sus actos ${ }^{28}$.

La misma duda sobre qué puede significaruna atribución de "responsabilidad" que no requiera atribución de intenciones permanece cuando pasamos por la -más reciente- interpretación ofrecida por Leonardo Eiff en su obra MerleauPonty, filósofo de lo politico. Reconstruyendo la posición merleaupontiana, Eiff señala: "la verdad de una acción... no descansa en [las] intenciones deliberadas [del agente], sino en el lugar que ocupa en un contexto dinámico. En otras palabras, la pregunta por la acción política es la pregunta por qué rol juega tal actor en la coyuntura"29. Volviendo sobre el caso de Bujarin, se nos dice que este "no puede verse como el actor de los resultados objetivos... de su práctica, pero no puede negar su práctica, y de nada sirve en politica decir 'no fue mi intención" 30 . Sin embargo el problema sigue siendo el mismo: ¿en qué sentido el actor político puede querer decir "no fue mi intención", pero esto "de nada le sirve"? ¿Con qué propósito el actor diria "no fue mi intención”? ¿En qué sentido la "verdad" de su acción no depende de sus intenciones? Naturalmente, la acción política no se reduce-como ninguna otra- a las intenciones de los suje-

\footnotetext{
${ }^{28}$ Una segunda alternativa sería, desde ya, concebir al adversario como uno que aceptara (1) pero negara la tesis empírica (2), pero tampoco en este caso se ve quién podría comprometerse con una tesis de este tenor; por lo demás, quien afirma que la atribución de responsabilidad presupone una atribución de intenciones no lo hace por negar premisas como (2); no necesita postular una omnipotencia de las intenciones sino, simplemente, que existen los fracasos, los resultados contrarios a lo que hemos intentado, pero que no somos responsables por ellos.

29 Eiff, L., Merleau-Ponty, filósofo de lo politico, Los Polvorines: Universidad Nacional de General Sarmiento-Córdoba/Universidad Nacional de Córdoba, 2014, p. 171, cursivas del autor.

${ }^{30}$ Ibid.
}

ARETÉ Revista de Filosofía, vol. XXVIII, N², 2016 / ISSN 1016-913X 
tos, las acciones tienen consecuencias y la existencia de estas consecuencias no queda denegada por afirmar que no ha sido nuestra intención producirlas. Si el actor político en cuestión estuviera afirmando "este resultado no fue mi intención, por lo tanto puedo negar mi práctica", es desde ya evidente que "de nada sirve" esta referencia a las intenciones: la práctica humana típicamente produce resultados, y ellos tienen una existencia mundana que subsiste de manera independiente de lo que haya intentado el agente. Los resultados de una acción pueden ser igualmente nocivos o catastróficos, independientemente de la inocencia subjetiva de la acción que condujo a aquellos y, desde este punto de vista, "de nada sirve" subrayar la inocencia en cuestión: los resultados nocivos no desaparecen. Sin embargo, en el fondo esto es simplemente una variación de la tesis (2) que hemos reconstruido arriba, solo subraya que la inocencia subjetiva "de nada sirve" a la hora de garantizar los resultados deseados. Lo que sigue sin ser aclarado, no obstante, es el paso crucial de (1) y (2) a (3). Lo que está en juego, si vamos a darle un sentido a la noción de una "responsabilidad histórico-política" que prescinde de una atribución de intenciones, no es si podemos negar una práctica, sino en qué sentido podemos considerarnos responsables de aquella. No es en absoluto evidente que "de nada sirva" apelar a la inocencia de las intenciones, cuando lo que está en juego es precisamente la atribución de una responsabilidad que -reiteremos- vaya más allá de la mera causación.

Por último, nuestras dudas siguen en pie cuando consideramos el acercamiento de Jérôme Melançon. Este autor vuelve sobre el análisis merleaupontiano sobre Bujarin ${ }^{31}$ y señala que "lo trágico de la politica" se debe a "la no-coincidencia entre el interior y el exterior, la maldición de no ver, y menos aun dominar, la imagen que ofrecemos a los otros, de no poder permanecer inocentes, el maleficio que hace que nuestra conducta, incluso justificada, pueda siempre ser condenable"32.

\footnotetext{
31 "Bujarin interpreta su rol. No lo escribió, es actor y no autor. Nadie, ni siquiera Stalin, es su autor: como mucho, podríamos decir que, en conjunto, sus predecesores y contemporáneos abrieron ciertas posibilidades. Teniendo un rol que encuentra en el seno de las cosas y de los otros, lo hace suyo, lo marca con su personalidad y con sus valores... Bujarin jamás eligió traicionar la revolución. Sin embargo, dado que encuentra al adversidad en el seno de los otros y de las cosas, sus acciones tomarán un sentido que no era aquel que él deseaba" (Melançon, J., Merleau-Ponty et la politique: aux marges de la philosophie, Tesis para grado de doctor (texto inédito), Universidad París-Diderot (París VII), 2010, p. 160), cursivas del autor. Hemos accedido al texto por gentileza del propio Dr. Melançon.

32 Ibid.
} 
Una vez más, el problema es en qué sentido "nuestra conducta puede ser condenable" al margen de las intenciones que puedan subyacer a ella. Si condenamos la conducta en cuestión en el sentido de considerarla perniciosa, una conducta cuyos resultados son contrarios a ciertos intereses o necesidades, no queda duda de por qué puede, de hecho, suscitar rechazo. Sin embargo, la noción de responsabilidad histórico-politica requiere que estemos hablando de un tipo específico de relación entre estos resultados y un agente que tendría que hacerse responsable de ellos. Y es esto lo que todavía no hemos podido clarificar.

4. Por qué Merleau-Ponty no puede evitar ser un "teórico de las intenciones": La contraposición entre el "verbalismo" y la exigencia de "realización de los valores"

Recapitulemos el recorrido que hemos hecho hasta aquí. Partimos de preguntarnos qué puede significar llamar "crimen" a una acción cuyos resultados sean dañinos, incluso catastróficos, pero sin hacer referencia alguna a intenciones y sin que ello lleve a reducir el término "crimen" a, simplemente, "fenómeno con consecuencias dañinas". Esto nos llevó a incluir también la dimensión de la responsabilidad subjetiva, pero se nos planteó un problema similar: qué puede significar, sin recurrir a intenciones, que exista algo así como responsabilidad en un sentido que no se reduzca a "conexión causal".

Sin embargo, hasta aquí nos hemos detenido exclusivamente en señalar la oscuridad que presenta esta noción de "responsabilidad histórico-política", oscuridad que los distintos intérpretes que hemos analizado no parecen contrarrestar. Por lo tanto, hemos buscado disolver posibles argumentos a favor de la "tesis de la evaluación objetiva de las acciones", pero no hemos intentado la vía más directa de presentar argumentos en contra de la tesis. Buscaremos ahora enfocarnos en esta segunda tarea.

Diremos, para anticipar nuestra línea argumental, que una noción de "crimen objetivo" es lisa y llanamente estéril desde el punto de vista de un acercamiento prescriptivo a la acción (un acercamiento que incluya exigencias, mandatos), y que justamente Merleau-Ponty intenta un abordaje de este 318 último tipo. Es cierto que el fenomenólogo hace evaluaciones sobre acciones que tuvieron lugar en momentos de la historia pasada -y emplea en ellas categorías como "crimen objetivo"- pero emprende esta tarea apoyándose en un acercamiento prescriptivo al problema de la acción, que se resume en su adhesión a la que llama una "regla marxista" de buscar en el mundo los medios para realizar (volver efectivos) ciertos valores como la libertad o la democracia. De esta exigencia se siguen -porque de lo contrario no sería una exigencia en ARETÉ Revista de Filosofia, vol. XXVIII, № 2, 2016 / ISSN 1016-913X 
absoluto- ciertas evaluaciones para las acciones, que según cumplan o no con aquella, resultarán condenadas o reivindicadas. Pero esto tiene consecuencias importantes: por el mismo carácter prescriptivo del enfoque, tendrá que apelar $a$ intenciones - puesto que todo lo que es posible exigir a un sujeto de acción es que intente obtener ciertos resultados- y calificar acciones según estas intenciones; inversamente, por más que Merleau-Ponty pueda también hacer evaluaciones sobre acciones pasadas, si estas evaluaciones no incluyen una exigencia a futuro -esto es, si de "A fue un crimen" no se sigue "no se debe, en el futuro, hacer acciones del tipo de A"-, entonces este tipo de evaluación es simplemente irrelevante para el acercamiento prescriptivo al problema de la acción. El punto es, en última instancia, que pese a las críticas de MerleauPonty a una "moral de las intenciones", todo abordaje prescriptivo, incluso el suyo, es en cierto modo una teoría de las intenciones.

A efectos de la discusión, es preciso explicitar que nos estamos apoyando en las tesis siguientes:

(i) Merleau-Ponty presenta, junto con sus evaluaciones retrospectivas de ciertas acciones, una prescripción, la cual asocia al marxismo y la cual él mismo suscribe: la exigencia -contra el "verbalismo" liberal consistente en la mera proclamación de ciertos valores- de buscar una "realización" de objetivos tales como la libertad o la democracia. Como tal, esta exigencia necesita referirse de un modo u otro a posibles acciones futuras. A diferencia de la utilización de otros tipos de criterios, de los que pudiésemos servirnos simplemente para evaluar hechos del pasado, presentar una exigencia significa plantear que, a futuro, las acciones deben ser acordes a ella.

(ii) Toda exigencia de alcanzar un resultado $\mathrm{R}$ es, en la medida en que se admite que la acción puede encontrar obstáculos, una exigencia de intentar alcanzar R, es decir, una exigencia de tener ciertas intenciones. Precisamente porque el éxito de una acción no está garantizado por ninguna actitud que pueda adoptar el sujeto agente, no forma parte de lo que pueda exigirsele; solamente podemos exigirle que intente alcanzar $\mathrm{R}$.

(iii) Un acercamiento prescriptivo a la cuestión de la acción, que establezca una cierta exigencia $\mathrm{E}$, instituye ipso facto una cierta evaluación de las acciones, según respondan o no a la exigencia en cuestión: desde el punto de vista de esta evaluación, una acción A será "criminal" (mala, indeseable, incorrecta, etcétera) en el sentido específico de oponerse a 
E, y "buena" (deseable, correcta, meritoria, etcétera) en el sentido de obedecer a $\mathrm{E}^{33}$.

El primero de los tres puntos que hemos distinguido debería estar fuera de discusión. El fenomenólogo efectivamente está interesado en defender nociones prescriptivas, mandatos, en su análisis sobre la acción, por más que su insistencia en soslayar la dimensión de las intenciones, y su referencia a casos del pasado, haga parecer que su interés es puramente histórico, retrospectivo. Por el contrario, Merleau-Ponty insiste en abordar los problemas prácticos teniendo en cuenta la exigencia de una realización de los valores. Para el fenomenólogo, interpretando en este punto a Marx, "una sociedad no es el templo de los valores-ídolos que figuran al frente de sus monumentos o en sus textos constitucionales... vale lo que valen en ella las relaciones del nombre con el hombre". "La pureza" de los principios de la sociedad liberal "no la absuelve; por el contrario, la condena si se comprueba que no existe en la práctica" 34 . De esto, Merleau-Ponty concluye que la "crítica marxista de las ideas liberales tiene tanta fuerza que si el comunismo estuviese abocado a la tarea de establecer... una sociedad sin clases de la cual hubiesen desaparecido, con la explotación del hombre por el hombre, las causas de las guerras y de las decadencias, sería necesario ser comunista" 35 .

Desde ya, queda por ver si efectivamente "la violencia que ejerce" el comunismo "es revolucionaria y capaz de crear relaciones humanas entre los hombres"36, pero este posible desacuerdo sobre los hechos no suspende el acuerdo de Merleau-Ponty sobre los principios prescriptivos en cuestión, ni la circunstancia de que es solo a partir de estos principios que, según afirma, resulta posible "comprender el problema comunista", expuesto en particular por los Juicios de Moscú ${ }^{37}$. Confluyendo con el mismo problema desde otro ángulo, el fenomenólogo agrega que, si hay una "maldición de la política", esta "consiste precisamente en... que debe traducir los valores en el orden de los hechos... Se dijo siempre; la política es el arte de lo posible", y esto, para Merleau-Ponty, "es un llamamiento a la seriedad de la politica; en lugar de

\footnotetext{
33 Podemos, por simplicidad, omitir las acciones que serian simplemente indiferentes, neutrales, con respecto a la exigencia en cuestión: lo que nos interesa en particular es que una exigencia instituye su propio concepto de lo que es condenable.

${ }^{34}$ Humanisme, p. x (trad., p. 8).

${ }^{35}$ Humanisme, p. xiii (trad., p. 12), cursivas del autor.

${ }^{36}$ Humanisme, p. xiii (trad., p. 12).

37 Cf. Humanisme, p. xiii (trad., p. 11).
}

ARETÉ Revista de Filosofía, vol. XXVIII, N² 2, 2016 / ISSN 1016-913X 
afirmar simplemente nuestros deseos, nos obliga a buscar dificilmente en las cosas la figura que deben asumir"38.

Encontramos formulaciones similares cuando Merleau-Ponty analiza el caso ficcional de Rubashov, siempre según esta "moral marxista": "la afirmación inmediata... de los valores" es, para Rubashov, "la más sutil de las mistificaciones, puesto que nos autoriza a abandonar a los hombres existentes y nos hace dejar la moralidad efectiva por una moralidad soñada". De acuerdo a esta interpretación del marxismo, entonces, "la única manera de ser fiel a los valores es dirigirse hacia el exterior para obtener en él, como decía Hegel, la realidad de la idea moral"' 39 .

Insistamos, pues, en nuestro punto: el análisis de la acción en MerleauPonty es (en la línea de lo que concibe como una "moral marxista") uno de tipo prescriptivo. Ahora bien, y con esto pasamos al segundo de los puntos que desglosamos al comienzo de este apartado, toda prescripción, toda exigencia, es una apelación a intenciones; incluso cuando se refiere explícitamente a resultados. Ella no puede ser más que una exigencia de intentar obtener estos resultados, una exigencia de, como dice el propio Merleau-Ponty, "buscar dificilmente en las cosas" la figura que debe asumir aquello que deseamos; es una exigencia de no limitarnos a simplemente "afirmar" tales deseos. No obstante, sería un sinsentido pensar que puede tratarse de una exigencia de obtener resultados si la concebimos en oposición a intentar obtener resultados. Comparemos las (en apariencia dos) exigencias siguientes:

1) Usted debe realizar en el mundo valores tales como la libertad o la democracia.

2) Usted debe intentar realizar en el mundo valores tales como la libertad o la democracia.

¿Cómo puede diferenciar un agente, en tanto destinatario del mandato, lo que debe hacer para cumplir con el mandato (1) y lo que debe hacer para cumplir con el mandato (2)? Después de actuar, este sujeto u otros, podrán

\footnotetext{
${ }^{38}$ Humanisme, pp. xxx-xxxi (trad., p. 29), cursivas del autor. Elegimos traducir "nos volontés" por "nuestros deseos" en lugar de "nuestras voluntades", como lo hace Rozitchner, a efectos de no confundir la "volonté" como facultad con las formas de su ejercicio, las orientaciones particulares de la voluntad.

${ }^{39}$ Humanisme, p. 8 (trad., p. 50). Asimismo, más adelante: "El marxista reconoció la mistificación de la vida interior, vive en el mundo y en la historia. En su opinión, la decisión... no es la afirmación inmediata de los valores que preferimos, sino que consiste en fijar el lugar de nuestra situación en el mundo, en volver a colocarnos en el curso de las cosas, en comprender bien y en expresar bien ese movimiento de la historia fuera del cual los valores resultan verbalismos, y únicamente por el cual tienen la posibilidad de realizarse” (Humanisme, p. 23 (trad., p. 64)).
} 
decir, en tiempo pasado, que este realizó ciertos valores, que obtuvo ciertos resultados o que, por el contrario, solamente lo intentó, pero fracasó. Sin embargo, esta perspectiva posterior ya no es la del agente en tanto que agente; ya nos encontramos en un plano en que la acción ya no está siendo hecha. Si un sujeto está efectivamente intentando alcanzar un cierto resultado -en oposición a simplemente "afirmar sus deseos", o a fingir intentar-, eso significa que está movilizando medios a su alcance para que el resultado efectivamente ocurra; en lo que cae bajo el alcance del agente en tanto agente, las condiciones de cumplimiento del mandato (1) son idénticas a las que corresponden a (2), y por lo tanto resulta absurdo pensar en un tipo de mandato que no sea un recurso a intenciones. Si podemos reprocharle al sujeto no haber obtenido los resultados exigidos porque no puso en juego todos los medios a su alcance, esto obviamente significa que no cumplió el mandato (1), pero al mismo tiempo significa que tampoco cumplió con (2). Podemos decir que el sujeto no estaba intentando realmente y la crítica se mueve, una vez más, en el plano de las intenciones. Tratar de ir más allá de ese plano y ordenar a un sujeto que su acción resulte exitosa-en virtud de las cadenas causales que ella inicia- es, lisa y llanamente, ordenarle algo que no es una acción, y por lo tanto es desconocer las condiciones minimas para que quepa hablar inteligiblemente de "exigencias".

Ahora bien, existe una forma de tratar de volver inteligible la insistencia merleaupontiana de desplazar la centralidad de las intenciones. Hemos visto más arriba que Merleau-Ponty contraponía la mera afirmación de los valores con su realización. Sin embargo, en por lo menos un pasaje, el fenomenólogo asimila esta contraposición con otra: nos habla de "la dura regla marxista que obliga a definir a un hombre no por sus intenciones, sino por lo que hace" ${ }^{40}$. Este pasaje permitiría entender por qué, según el fenomenólogo, el marxismo tiene que comprometerse con una evaluación de los resultados y no de las intenciones, lo que significa al mismo tiempo que se está sometiendo la noción de "intenciones" a una torsión bastante sorprendente: significa que se da por sentado que las "intenciones" son algo así como un estado extático de contemplación de valores. No obstante, este supuesto es enteramente forzado. Una intención siempre es intención-de-algo, con lo cual el sujeto que intenta es alguien que, lejos de desentenderse de las consecuencias de sus actos, busca obtener, justamente, tales consecuencias ${ }^{41}$.

\footnotetext{
40 Humanisme, p. 8 (trad., p. 50), cursivas del autor.

${ }^{41}$ Merleau-Ponty parece en este punto olvidar lo que el más característico de los teóricos de las intenciones (nada menos que Kant) explicitaba al comienzo mismo de la Fundamentación de la 
Pasemos al tercero y último de los puntos que hemos desglosado más arriba. Si Merleau-Ponty suscribe un tipo de exigencia práctica, esto tiene que implicar una cierta distinción evaluativa entre dos tipos de acciones -entre deseables o indeseables, buenas o malas-, según si ellas cumplen o no con aquella; sin esta condición, no se ve en absoluto en qué sentido estariamos en presencia de una exigencia: solo podemos comprender, y por tanto obedecer $a$, una exigencia, si entendemos qué es lo que ella nos insta a hacer y de qué nos insta a abstenernos. Como fuere que llamemos a las acciones que caigan bajo un lado u otro de la clasificación, la clasificación en cuestión tiene que existir. Desde este punto de vista, plantear la exigencia de una realización de ciertos valores fundamentales (democracia, libertad, etcétera) significa instituir la clasificación según la cual son "buenas" (deseables, correctas) las acciones que efectivamente cumplen con tal exigencia, y "malas" (indeseables, incorrectas) las que no la cumplen. Ahora bien, si -como hemos argumentado más arriba- no podemos distinguir entre exigir que se haga algo y exigir que se intente hacer algo, en consecuencia el propio Merleau-Ponty tiene que evaluar aprobatoriamente, como "buenas" acciones -seguramente no como "crimenes" o "traiciones"-, aquellas acciones que cumplan con la exigencia de intentar realizar ciertos valores, incluso si tales acciones terminan en el fracaso. Que el juicio concierna a la intención y no al resultado es el costo de plantear un abordaje prescriptivo, incluso si no se lo llama "moral". Si toda exigencia necesita ser una apelación a intenciones, entonces el cumplimiento de la exigencia consiste en tener esas intenciones, no en tener éxito. Un juicio que pretenda, forzando un poco el vocabulario, hablar condenatoriamente de "crimen" en virtud simplemente del fracaso de la acción, puede servir, en el mejor de los casos, para una evaluación post factum, pero no puede cumplir ningún rol desde el punto de vista del mandato práctico.

metafisica de las costumbres: una intención no debe ser confundida con una ficción de intención. "La buena voluntad es buena... únicamente por el querer, esto es, es buena en sí... Aun cuando por un especial disfavor del destino... le faltase enteramente a esa voluntad la capacidad de sacar adelante su propósito, si con el mayor empeño no pudiera sin embargo realizar nada, y solo quedase la buena voluntad (desde luego, no un mero deseo, o algo así, sino como el acopio de todos los medios, en la medida en que están en nuestro poder), con todo ella brillaria entonces por sí misma" (Kant, I., Fundamentación de la metafisica de las costumbres, Barcelona: Ariel, 1999, p. 119 (Ak. p. 394)), cursivas del autor. 


\section{Subordinación de medios a fines, o mandato moral "no contextual"}

Habiendo partido del problema de si nociones como "traición" o "crimen" pueden, en el terreno histórico-político, aplicarse sin atribución de intenciones, y habiendo llegado al mismo problema con respecto a la noción de "responsabilidad", encontramos que una segunda contraposición analizada por MerleauPonty -entre la realización de los valores y su mera proclamación- no avalaba, sino que contribuia a minar, sus dos tesis "objetivistas" en lo que concierne al análisis según resultados frente al análisis según intenciones. No obstante, al analizar la cuestión de la realización de valores no hemos podido evitar toparnos con una tercera contraposición. Intentaremos mostrar ahora que la argumentación merleaupontiana sobre este punto tampoco funciona como aval para defender sus tesis "objetivistas".

Consideremos un pasaje clave en que se encuentra este problema. Comparando el liberalismo occidental con el régimen vigente en la URSS, el fenomenólogo señala que "[u]n régimen nominalmente liberal puede ser realmente opresivo. Un régimen que asume su violencia podria encerrar un humanismo mayor. Oponer aqui al marxismo un 'primero la moral' es ignorarlo en lo que ha sostenido con mayor razón" ${ }^{2}$. Ahora bien, cuando se nos habla aquí de un "primero la moral”, nos preguntamos ¿cuál moral es la que cabría, con sentido, oponerle al marxismo? Seguramente no se puede tratar de la "moral de las intenciones", puesto que, según acabamos de argumentar, toda exigencia en el terreno práctico es una apelación a intenciones. Pero cabe leer a partir de este y otros pasajes la referencia a una contraposición distinta de las dos que hemos visto: la existente entre, por un lado, un acercamiento a la acción política que privilegia los resultados en el mediano o largo plazo, que "contextualiza" la acción con respecto a ellos, frente a, por otro lado, "la moral", que no aceptaría este tipo de contextualización y para la cual ciertos tipos de acciones (la violencia, el engaño) pueden ser condenadas "recortándolas" de su contexto. En resumidas cuentas y al margen de las precisiones de Merleau-Ponty sobre este punto en lo que se refiere al marxismo, se trata de la contraposición entre pensar o no, que es el fin el que justifica ciertos medios. Es con este último problema que puede conectarse el marxismo tal como aparece descrito cuando Merleau-Ponty decía que para Rubashov "la verdadera moral se burla de la moral"43: esta segunda es la que nos plantea mandatos incondicionales, la que no toma en consideración

42 Humanisme, pp. x-xi (trad., p. 9), cursivas del autor.

${ }^{43}$ Humanisme, p. 8 (trad., p. 50), cursivas del autor. 
las intrincadas y paradójicas vías que pueden ser necesarias para realizar ciertos valores humanos. Es por esta legitimación de ciertos medios a partir de la necesidad planteada por los fines que, "[e]n nombre de las exigencias de la historia", Rubashov "defendió la dictadura y sus violencias contra las almas bellas"44.

Estamos, por lo tanto, frente a la vieja cuestión de la relación entre los fines y los medios; esto es, al problema de si acciones que, tomadas por si mismas fuera de contexto, resultan condenables, no son, por el contrario moralmente exigibles cuando las analizamos desde la perspectiva de las consecuencias que buscamos obtener a través de ellas. El debate pasa, de esta manera, al plano de un tipo de ética utilitarista (aunque Merleau-Ponty no utilice esta terminología), y con ello, hereda sus dilemas: por un lado, "al enseñar la no-violencia se consolida la violencia establecida, es decir, un sistema de producción que torna inevitables la miseria y la guerra. Sin embargo [por otro lado] si se entra en el juego de la violencia, existe la posibilidad de quedarse en ella para siempre. ...La astucia, la mentira, la sangre derramada, la dictadura, se justifican si hacen posible el poder del proletariado, y en esa medida solamente"45. Justamente porque el marxismo no se propone "quedarse en la violencia", dado que este "se abre sobre un horizonte de futuro donde el "hombre es para el hombre el ser supremo", su "tarea esencial... será... buscar una violencia que se supere en el sentido del porvenir humano" ${ }^{46}$.

Pero este paso por la violencia para suprimir la violencia no hace del marxismo, según la reconstrucción que de él nos presenta Merleau-Ponty, una doctrina política según la cual el fin justifica los medios: "No todos los medios son buenos para realizar este universo"; "no puede ser cuestión de utilizar sistemáticamente la astucia con los proletarios y ocultarles... el verdadero juego..., puesto que la conciencia de clase sería disminuida y la victoria del proletariado se veria comprometida" ${ }^{47}$. Esta incompatibilidad con algunos medios no suprime, sin embargo, el problema de fondo según el cual la acción marxista no puede prescindir de cierta "inmoralidad" en lo que concierne a ciertas acciones tomadas por sí mismas ("la mentira, la sangre derramada, la dictadura").

\footnotetext{
${ }^{44}$ Ibid. Nos apartamos aquí de la traducción de Rozitchner, quien vierte "belles âmes" como "minorias selectas".

${ }^{45}$ Humanisme, p. xiv (trad., p. 13).

${ }^{46}$ Humanisme, pp. xiii-xiv (trad., pp. 12-13), cursivas del autor. Y en otro pasaje: "El leninista, puesto que persigue la acción de clase, abandona la moral universal, pero esta le será devuelta en el nuevo universo de los proletarios de todos los países" (Humanisme, p. xv (trad., p. 13)).

47 Ibid. Rozitchner traduce aquí literalmente "Tous les moyens ne sont pas bons" por "Todos los medios no son buenos").
} 
Ahora bien, si estamos abordando la cuestión de si el fin justifica o no ciertos medios, esta contraposición obviamente no se superpone con la que existiria entre la tesis según la cual habría crimenes y responsabilidades “objetivos" y la tesis contraria, según la cual las acciones deben ser juzgadas por sus intenciones. De hecho, en ambos casos -es decir, tanto en el de quien considere que un cierto objetivo justifica la violencia o la mentira, como en el de quien adopte la condena incondicional de tales medios- lo que estaremos juzgando es si debemos o no proponernos-si debemos o no intentarlograr-ciertos objetivos a través de ciertos medios "impuros". Si respondemos positivamente a esta pregunta, el tipo de mandato moral al que estaremos inclinados nos dirá que debemos intentar realizar ciertos valores cueste lo que cueste (laxitud pese a la cual podemos perfectamente fracasar en nuestros propósitos); si respondemos negativamente, el mandato moral también será uno que nos ordenará intentar realizar ciertos resultados sin ir más allá de ciertos medios aceptables (un desiderátum en el cual también podemos tener éxito o no). No obstante, una vez más, esta es una diferencia que no necesita -ni puede- salir de la esfera de la apelación a lo que debemos intentar.

Así las cosas, tendremos que seguir buscando qué puede tener en mente Merleau-Ponty para sustituir un análisis de la acción según sus intenciones por sus propias tesis "objetivistas".

6. Dependencia o independencia de los juicios de hecho respecto a los juicios de valor

Pues bien, hay una argumentación paralela a la que hemos estado reconstruyendo, cuyas relaciones con esta no son clarificadas por Merleau-Ponty, pero que sí presenta consecuencias relevantes para defender las tesis "objetivistas" del fenomenólogo. Como intentaremos mostrar, la reticencia merleaupontiana a aceptar un análisis según intenciones tiene uno de sus puntos de apoyo en una implícita contraposición -la cuarta que entra en juego en su libro- entre, por un lado, su propia tesis sobre una no-independencia entre juicios de hecho y juicios de valor, y, por otro lado, la más habitual tendencia a diferenciar entre la apreciación epistémica de una situación y su valoración axiológica. Veamos cómo funciona en concreto esta argumentación; esto es, cómo Merleau-Ponty sustenta el rechazo a la moral de las intenciones en el rechazo a la idea de un mero error epistémico de quienes han creído simplemente resignarse a una situación dada. 
La articulación merleaupontiana de los dos problemas puede reconstruirse en una serie de pasos que el filósofo francés desarrolla haciendo una analogía entre los Juicios de Moscú y las condenas propias de la "depuración" francesa posterior a la ocupación nazi. En rigor, en el caso del colaboracionismo tanto como en el de los Juicios, el ejemplo histórico es extremadamente polémico. Vamos a suponer, sin embargo, en aras de la evaluación del argumento -y sin comprometernos con tesis historiográfica alguna-, que efectivamente han existido los casos de quienes colaboraron, como señala Merleau-Ponty, en aras de lo que creían que era el "interés del país". Por ejemplo, como señala Raymond Aron criticando al fenomenólogo, quienes creían que era necesario subordinarse a los alemanes no para renunciar a la lucha contra estos, sino precisamente para poder retomarla más tarde ${ }^{48}$.

Vamos al primer paso, la puesta en escena. Nuestro autor señala justamente los márgenes, según él excesivos, a los que da lugar un análisis de la acción según las intenciones, puesto que, ante una acción bienintencionada cuyos resultados fueran sin embargo trágicos, este análisis complementa la buena intención con el error epistémico, lo cual, según Merleau-Ponty, comportaría alguna forma de absolución. Aunque para él "[e]s posible que ni Pétain ni Laval hubieran decidido entregarse a Alemania por el dinero, por conservar el poder o para hacer prevalecer determinada politica", ello no obstante, "aun si no hubiesen cometido falta alguna en ese sentido", "[a]un si quedara establecido que no alentaban otro móvil que el interés del país, ...aun si, según toda probabilidad, la Alemania de 1940 estaba en vísperas de una victoria definitiva", para Merleau-Ponty "nos negariamos a absolverlos como hombres que simplemente se han equivocado", "la decisión que tomaron de colaborar no nos parecería menos criminal"49.

Por tanto, tenemos que, para hacer justicia a la posición que desea rechazar, Merleau-Ponty admite como hipótesis la de que efectivamente pudiese

\footnotetext{
48 Justamente el punto de Aron va contra la interpretación merleaupontiana, en la medida en que el autor de El opio de los intelectuales sí considera que la evaluación moral tiene que guiarse por una reconstrucción de intenciones, y no debe variar según los distintos resultados que nos arroje la historia. Así es que distingue: "Quien estimaba que el armisticio [de 1940] preservaba mejor las oportunidades de Francia... quizá se haya equivocado. Su error no se transforma en traición con la victoria aliada. Quien deseaba el armisticio... para preparar la reanudación del combate, no era un traidor ni se ha transformado en ello. Quien quería el armisticio para que Francia cambiara de bando, era un traidor, desde ese momento, con respecto a la Francia de 1940 y de 1945" (Aron, R., L'opium des intellectuels, París: Calmann-Lévy, 1955, p. 142; consúltese la traducción El opio de los intelectuales, Buenos Aires: Ediciones Siglo Veinte, 1979, p. 135).

${ }^{49}$ Humanisme, pp. 41-42 (trad., pp. 82-83), cursivas del autor.
} 
decirse que Alemania estaba en 1940, "según toda probabilidad" en vísperas de una victoria. Esta admisión merleaupontiana es clave, puesto que, si no desea presentar una caricatura de la posición "intelectualista" que está discutiendo - "intelectualista”, aclaremos, únicamente en un sentido según el cual la acción con resultados condenables puede ser simplemente un error- tiene que admitir como al menos concebible el escenario de la simple equivocación. El partidario de la interpretación en términos de error epistémico no está afirmando que no haya nada que reprochar en la actitud de quien colaboró con la ocupación; simplemente señala que tenemos que tomar en consideración el significado que esta acción tuvo, desde sus propias perspectivas cognitivas, para quienes se involucraron en ella, y remarca también que existe una diferencia pertinente entre una evaluación equivocada de la propia situación histórica y una decisión consciente, calculada, a favor de los resultados que consideramos condenables. Asi, afirma que existe un margen para problemas especificamente epistémicos, incluso cuando las consecuencias de tales errores sean terribles. Se trataria, no de una aprobación de la conducta de los colaboracionistas, sino de la constatación, desde ya muy pesimista, de que los sujetos de creencias y acción no estamos eximidos de antemano de actuar, por simple ignorancia o estupidez, de modos que llevan a resultados catastróficos para terceros ${ }^{50}$.

Frente a esta tesis, como hemos visto, el autor no comienza por decirnos que sea un sinsentido la hipótesis de que "según toda probabilidad" Alemania fuese a ganar la guerra; más bien nos dice que, incluso si las probabilidades hubiesen arrojado esa imagen de la situación, la actitud colaboracionista habria preservado el mismo disvalor moral. Sin embargo, en segundo lugar, cuando el fenomenólogo tiene que fundamentar este "incluso si...", más bien

\footnotetext{
${ }^{50} \mathrm{Y}$ esta lectura criticada por el fenomenólogo, la cual colocaría al colaboracionismo en el plano del fallo epistémico, no es por otro lado significativamente distinta de la que el mismo MerleauPonty haria, muy poco tiempo más tarde, para referirse a quienes defendian -bajo el ropaje del "socialismo realmente existente"- al régimen concentracionario de la Unión Soviética. Escribe en 1950: "Si nuestros comunistas aceptan los campos de concentración y la opresión, es porque esperan de ella la sociedad sin clases por el milagro de las infraestructuras. Se engañan, pero eso es lo que ellos piensan. Cometen el error de creer en la oscuridad, pero eso es lo que creen" (Merleau-Ponty, M., Signes, París: Gallimard, 1960, p. 433; traducción castellana: Signos, Barcelona: Seix-Barral, 1973, p. 332), cursivas del autor. No pareceria justo afirmar que esta constatación merleaupontiana de un error epistémico en los "estalinistas honestos" sea en absoluto una defensa de la posición de estos últimos; sí se trata -cosa que resulta mucho menos clara en la evaluación del colaboracionismo en Humanismo y terror- de la constatación pesimista de que la reorientación de las acciones ajenas puede requerir menos de una corrección de sus deseos, sus intenciones, que de una aclaración de sus errores. En este caso, se trataría de minar la confianza en el "milagro de las infraestructuras", más que de desalentar (porque no la habria) una evaluación sobre el autoritarismo y el terror como valiosos por sí mismos.
} 
queda redefinida la noción misma de esta "probabilidad"; ya no se concede al oponente -quien habla de error epistémico- que pudiese hablarse, en los propios términos en que este planteaba el problema, sobre una probabilidad objetiva de la victoria alemana, una probabilidad que pudiese simplemente constatarse-como en cualquier otra área del conocimiento- para luego, sobre la base de este conocimiento hasta aquí neutral, tomar una posición. De acuerdo a Merleau-Ponty, más bien no hay, en rigor, un conocimiento de la situación histórica que preceda a la decisión práctica, sino que tal presunto conocimiento ya viene permeado por la toma de posición: "cuando se condena como criminal la elección de los colaboracionistas", ello quiere decir "que en historia ninguna situación de hecho aparece como absolutamente necesaria, y que la proposición 'Alemania ganará probablemente la guerra', no podía ser en 1940 una simple comprobación, que esta proposición aportaba a un acontecimiento todavía incierto el sello de lo irrevocable", y que, cuando vemos un acontecimiento bajo esta forma, "el juicio aparentemente inocente que comprueba lo posible en realidad dibuja un juicio de valor"s1.

No obstante, todavía hay más complicaciones, pues, en tercer lugar, el fenomenólogo necesita justificar la tesis que acaba de introducir. Esto quiere decir que ahora sabemos que en 1940 no podía saberse que Alemania fuese a ganar la guerra y que asumir ese triunfo de los nazis era menos una pura constatación que una toma de partido, con lo cual el autor tiene que admitir que su tesis sobre los sujetos que estaba evaluando se apoya en una perspectiva histórica diferente a la de ellos: se apoya en la perspectiva de la que él mismo dispone al poder juzgar la historia a la luz de la derrota del Eje. En efecto, “¿cómo sabemos todo esto en lo que concierne a los acontecimientos de 1940? Por la victoria aliada". Es ella la que "demuestra permanentemente que la colaboración no era necesaria, la hace aparecer como una iniciativa y la transforma, a pesar de lo que haya sido o creido ser, en voluntad de traición"52.

Estas últimas líneas complican significativamente el cuadro del análisis, ya que, ante todo, el fenomenólogo nos dice con toda la explicitud posible que es por la victoria aliada, y no con independencia de ella, que sabemos que la colaboración era una alternativa entre otras. El autor no afirma que, cualquiera hubiese sido el desenlace de la guerra, nuestro punto de vista acerca de los colaboracionistas sería el mismo ${ }^{53}$. Para el fenomenólogo, es solo la derrota del

\footnotetext{
${ }^{51}$ Humanisme, pp. $42-43$ (trad., p. 84), cursivas del autor.

52 Humanisme, p. 43 (trad., p. 84), cursivas del autor.

53 Cosa que sí afirma Lukács, quien se pregunta retóricamente: “¿Sería menor la gloria de los partisanos de la Resistencia, se atenuaría la ignominia de los colaboradores, si Hitler hubiera
} 
nazismo la que prueba que otras opciones eran posibles -pero entonces, por principio, tal prueba no resultaba accesible a los sujetos cuyas decisiones se está sometiendo a evaluación-.

En consecuencia, y siempre según las premisas del propio Merleau-Ponty, tenemos aquí un dilema: o bien estos sujetos actuaban realmente en la ignorancia (puesto que no podemos atribuirles un conocimiento que solo resultó posible años más tarde y entonces no se ve de qué manera descartar la evaluación de su comportamiento en términos de que sus acciones, de consecuencias innegablemente terribles, se basaron en una mala apreciación epistémica); $o$ bien se podía ya en 1940 contar con la derrota alemana, pero entonces lo que Merleau-Ponty no puede sostener es que esta derrota solo se llegó a revelar como posible una vez consumada.

No se ve de qué manera el autor puede aferrarse a tesis en principio incompatibles, pero inmediatamente después encontramos, en cuarto lugar, que el eje de la discusión se ha desplazado: la diferencia entre lo que se sabía en el momento de la acción -en nuestro ejemplo, 1940-y lo que llega a revelarse con posterioridad -en este caso, en 1945- no es, bajo esta reformulación, que un evento que inicialmente parecía imposible se revelara posible, sino simplemente una diferencia de grado: que aquello que inicialmente se mostraba como más probable luego se revele como menos probable; así, quienes creían estar marchando "con la corriente" finalmente se encontraron en la situación opuesta. Este es el único modo en que parece poder comprenderse la continuación del texto:

La historia tiene una especie de maleficio: solicita a los hombres, los tienta, ellos creen marchar en el sentido en que ella marcha, y de pronto se les oculta, el acontecimiento cambia, demuestra con hechos que otra cosa era posible. Los hombres a los cuales abandona y que no pensaban ser otra cosa que sus cómplices son de pronto los instigadores del crimen que la victoria les inspiró. Y no pueden buscar excusas ni descargarse de una parte de la responsabilidad, puesto que en el mismo momento en que seguian la pendiente aparente de la historia, otros decidian subir por ella, comprometian sus vidas sobre otro porvenir. No estaba, pues, por encima de las fuerzas humanas ${ }^{54}$. Tenemos entonces, recapitulando, que incluso si los presuntos colaboracionistas "sin malas intenciones" se hubiesen apoyado en ciertas presuntas evidencias históricas para guiar su curso de acción, eso no convertiría su decisión en una

triunfado? Es la Realpolitik reaccionaria, de la cual el fascismo fue el punto culminante, la que hace de la eficacia un criterio exclusivo" (Lukács, G., o.c., pp. 210-211).

54 Humanisme, p. 43 (trad., pp. 84-85). 
explicable en términos de error epistémico; que esto se debe a que no hay, realmente, evidencias incontestables en el marco de la historia; pero que, por otro lado, si no hay evidencias incontestables es porque podemos desacreditarlas desde un punto de vista que, justamente, no es el de aquellos sujetos situados cuya respuesta en situación es la que queremos evaluar.

Tratemos de desenmarañar este razonamiento, sirviéndonos para ello de contextualizar los pasajes que acabamos de ver con otros que hemos citado previamente. La fundamentación de las tesis merleaupontianas parecería ser la siguiente:

1) No existe una "ciencia del futuro"; esto es, nunca disponemos más que de lineamientos generales que, a grandes rasgos, nos permiten orientarnos ante las necesidades de la acción, pero no podemos realizar prognosis históricas exactas.

Por lo tanto,

2) Siempre permanece el riesgo de una distancia entre los resultados que nos proponemos con nuestra acción y los que de hecho resultan de ella; no podemos garantizar de antemano que las consecuencias futuras de nuestras acciones se desenvolverán en el sentido que prevemos en el presente.

Hasta aquí, como vemos, la imposibilidad de las predicciones históricas exactas parecería apuntar en el sentido de una "absolución" moral de aquellos -todos nosotros, en rigor- que actúan sin poder prever por completo las consecuencias de nuestros actos. Sin embargo, la premisa (1) también tendría una consecuencia que apunta en la dirección contraria. Precisamente porque nunca tenemos más que lineamientos generales sobre el futuro, entonces,

3) Siempre necesitamos decidir en qué perspectiva de acción leer los indicios que hallamos en la realidad; ellos nunca apuntan inequivocamente en una única dirección.

Así, nunca es únicamente a partir de los datos disponibles que hacemos nuestras elecciones prácticas; hay algo más que este elemento estrictamente cognitivo. Entonces, según Merleau-Ponty,

4) Las pretendidas decisiones a partir de los datos disponibles encierran, en rigor, un juicio de valor, por el cual somos moralmente imputables.

Sin embargo, no queda claro en todo esto que el rol de los "juicios de valor" realmente le permita al fenomenólogo moverse en un espacio entre la referencia al error cognitivo $y$ la referencia a algo del tipo de las intenciones. En efecto, como veremos, bajo una de las dos lecturas posibles no queda claro por qué cierta orientación valorativa no daría lugar a un mero error de aprecia- 
ción, un error epistémico; bajo la segunda lectura, no logramos descubrir, a la inversa, por qué la noción de "juicios de valor" sería realmente heterogénea a la de intenciones; Merleau-Ponty necesitaría seguir recurriendo, pese a todos sus rodeos, a una condena de las motivaciones de los individuos.

Estas dos posibilidades surgen de preguntarnos si los "juicios de valor" en cuestión son realmente orientaciones conscientes, la clase de dato que puede entrar en una deliberación, o no lo son. Supongamos, como primera alternativa, que de hecho no lo son: los colaboracionistas no estaban optando por el fascismo de manera consciente; los "juicios de valor" operaban únicamente como afectando, "de espaldas" al agente, la aprehensión epistémica que este hacía de sus circunstancias; de alli la referencia a un "juicio aparentemente inocente que comprueba lo posible", pero que "en realidad" es otra cosa55. El sujeto que cree estar haciendo una simple constatación de una situación de hecho -como lo sería la de la irrevocabilidad de la victoria alemana de 1940-, en rigor estaría siendo afectado -pero sin saberlo- por sus "deseos" o "valores" a la hora de jerarquizar la información pertinente. Parece necesario hablar de una jerarquía, de una evaluación, de los datos, porque de existir únicamente estos últimos, entonces nuevamente lo que condenariamos sería solo un error de apreciación: alguna de las partes no estaba bien informada. Pero si asumimos por hipótesis que ambas partes, colaboracionistas y miembros de la Resistencia, conocian a grandes rasgos los mismos datos de la coyuntura -coyuntura que era ambigua y presentaba puntos de apoyo para cualquiera de las dos tomas de partido-, podría decirse quizá que mientras los primeros habrian decidido jerarquizar un dato como la derrota del Ejército francés, los resistentes habrian optado por darle mayor relevancia a la potencia militar de las naciones aliadas contra el nazismo, y ninguno de estos datos sería ilusorio. Ambos "campos" dispondrian así de la información pertinente, pero ella solo puede convertirse en un soporte para un curso de acción en lugar de otro cuando introducimos un elemento que

\footnotetext{
55 Si bien Merleau-Ponty no profundiza esta línea de análisis según la cual los juicios de valor funcionan como condicionantes inconscientes de nuestro conocimiento, en rigor es una que ha sido trabajada por distintos abordajes en el marco de la sociología del conocimiento, en algunos casos desde un marxismo del cual el fenomenólogo habría podido sentirse cercano. Es el caso del filósofo Lucien Goldmann, quien, contra las exigencias de cientificidad positivista de la sociologia durkheimniana, muestra cómo ella misma, por su orientación conservadora, "[ve] claramente las debilidades lógicas de una argumentación revolucionaria y cometa, a su vez, los mismos errores lógicos cuando se trata de defender sus propios valores" (Goldmann, L., Las ciencias humanas y la filosofia, Buenos Aires: Nueva Visión, 1984, p. 25). Mutatis mutandis, lo que Goldmann argumenta aquí respecto de los juicios del científico podría aplicarse, con más fuerza aun, a las evaluaciones que hace un sujeto no-científico acerca de la coyuntura en que vive.
} 
no es epistémico, sino axiológico; en última instancia, fueron los valores de los colaboracionistas los que los hicieron decidir como lo hicieron. Sin embargo, estos valores habrian actuado "escondidos" bajo un aparente acto de conocimiento, puesto que lo que se jerarquiza, en un caso como en el otro, siguen siendo datos; la información misma sobre la coyuntura habría aparecido a los colaboracionistas, de este modo, como si fuera inevitable la victoria de Hitler, y no como si ellos mismos estuviesen contribuyendo a un desenlace evitable.

Ahora bien, bajo esta lectura, los juicios de valor funcionan de modo análogo a lo que típicamente consideramos un prejuicio, haciendo que creamos que los datos mismos se orientan a favor de una descripción u otra, pero sin entrar como premisas explícitas en nuestras evaluaciones. Podemos entender su conexión con la esfera de las orientaciones prácticas -en tanto existen prejuicios conservadores, revolucionarios, liberales, etcétera- pero, por hipótesis, estos prejuicios serían formas de percibir la realidad, sin que mediara en ello elección alguna del sujeto, sino un error. Naturalmente, llamarlos "error" no representa un intento de minimizar las espantosas e inhumanas consecuencias que pudiese tener el colaboracionismo: simplemente, estamos tratando de llevar hasta el final la argumentación del propio Merleau-Ponty según la cual, aparentemente, lo que llama "juicio de valor" contaminaría el modo mismo en que creemos conocer la realidad.

Hasta aquí, pues, la primera opción. Sin embargo, predeciblemente, hay una segunda lectura que casi se nos impone al considerar la primera. Porque, en rigor, en tal lectura los "juicios de valor" han quedado reducidos al rango de prejuicios; puede ser claro que no somos responsables de lo que se sitúa más acá de nuestra toma de conciencia, pero también que, ipso facto, ello deja de calificar como "juicio". Si estos juicios son realmente tales, esto es, si involucran una toma de posición consciente de parte del sujeto, la atribución que Merleau-Ponty hace de ellos a los colaboracionistas significa que el sujeto que elige colaborar con el invasor prefiere que su país sea gobernado por los nazis -o que, en todo caso, no lo considera una perspectiva tan grave-. Aquí no se podría decir que estemos en presencia de un error cometido de buena fe, sino de una adhesión consciente y, en consecuencia, la condena del colaboracionista en términos no solo epistémicos sería razonable, pero precisamente porque hemos repuesto, para condenarlo, una dimensión subjetiva sobre lo que el sujeto prefiere, lo cual no se ve sustancialmente diferente a un análisis en términos de intenciones. ¿No nos está diciendo Merleau-Ponty aquí, precisamente, que si no podemos absolverlos como sujetos que simplemente "estaban equivocados" es porque 
hacian una valoración positiva del nazismo y que, en consecuencia, debemos condenarlos en virtud de esta orientación subjetiva que constatamos en ellos? Como se notará, pues, tampoco bajo esta segunda alternativa parece resultar sostenible la propuesta de un espacio "intermedio" entre la referencia al error cognitivo y las motivaciones de la voluntad.

\section{Conclusiones}

El primer lugar: Merleau-Ponty nos presenta un intento de determinar una forma específica de evaluación de las acciones, que se aplicaría al plano histórico-político por oposición al jurídico, que haría abstracción de las intenciones de los agentes y que tomaría en consideración los resultados de sus acciones al proyectarlos hacia eventos posteriores. No obstante, no queda claro cómo esta noción de "crimen objetivo" podría significar algo más que "acción con consecuencias dañinas". Si la completamos poniéndola en conjunción con una segunda tesis, según la cual existiría una "responsabilidad objetiva", es esta última la que, en ausencia de una atribución de intenciones, parecería ser indistinguible de la mera causación.

En segundo lugar: peor aún para la propuesta merleaupontiana, la defensa de la "exigencia marxista" de "realizar en el mundo" nuestros valores, como contrapuesta al verbalismo que se limitaría a proclamarlos, es, precisamente en tanto exigencia, una apelación a lo que debemos intentar lograr; el cumplimiento de esa exigencia consiste por lo tanto en tener ciertas intenciones, y en consecuencia Merleau-Ponty, en tanto plantee este mandato, está ipso facto evaluando acciones según la intención que se manifiesta en ellas, no según sus resultados. Pretender hacer exigencias sobre las consecuencias causales no calculadas de una acción es, justamente, exigir algo que no es una acción, y por lo tanto no comprender la noción misma de "exigencia".

En tercer lugar: respecto del problema de una moral que exija la subordinación de la evaluación de los medios a la de los fines, en oposición a aquella que no lo haga, nuevamente no puede tratarse más que de una apelación a

334 intenciones, no a resultados. Lo que varía en un caso o en otro es de qué modo debemos intentar llegar a cierto fin.

Por último: la vía de crítica a la "moral de las intenciones" a través de la tesis de la no-independencia entre los juicios de valor y los juicios de hecho no parece suficientemente fundamentada, en virtud del carácter ambiguo que alli cumplen aquellos: si se trata de prejuicios inconscientes que nublan nuestra 
apreciación de una coyuntura, queda por demostrar por qué eso no es un tipo de error epistémico; si se trata de auténticos juicios, no queda claro por qué serian heterogéneos a las intenciones.

\section{Bibliografia}

Aron, R., L'opium des intellectuels, París: Calmann-Lévy, 1955. (Traducción castellana: El opio de los intelectuales, Buenos Aires: Ediciones Siglo Veinte, 1979.)

Danto, A., "Oraciones Narrativas", en: Narración y conocimiento, Buenos Aires: Prometeo Libros, 2014.

Eiff, L., Merleau-Ponty, filósofo de lo politico, Los Polvorines: Universidad Nacional de General Sarmiento-Córdoba/Universidad Nacional de Córdoba, 2014.

Goldmann, L., Las ciencias humanas y la filosofia, Buenos Aires: Nueva Visión, 1984.

Hubeny, A., “Jouer un rôle'. Action politique et responsabilité historique”, en: Ronald Bonan (ed.), Merleau-Ponty: de la perception à l'action, Aix de Provenza: Universidad de Provenza, 2005.

Kant, I., Fundamentación de la metafisica de las costumbres, Barcelona: Ariel, 1999.

Kolakowski, L., "Obsolete Therefore Instructive", en: The New York Review of Books, v. XV, 4 (1970), pp. 23-24.

Melançon, J., Merleau-Ponty et la politique: aux marges de la philosophie, Tesis para grado de doctor, inédito, Universidad París-Diderot (París VII), 2010.

Merleau-Ponty, M., Humanisme et terreur, 8va. edición, París: Gallimard, 1947. (Traducción castellana: Humanismo y terror, Buenos Aires: La Pléyade, 1965).

Merleau-Ponty, M., Signes, París: Gallimard, 1960. (Traducción castellana: Signos, Barcelona: Seix-Barral, 1973).

Wiggins, O.P., "Political Responsibility in Merleau-Ponty's Humanism and Terror", en: Man and World, v. XIX (1986), pp. 275-291. http://dx.doi.org/10.1007/BF01249365

Recibido: $18 / 03 / 15$

Aceptado: 16/02/16 